Proceedings

\title{
Extracts from Nicotiana glauca induce apoptosis through caspases in skeletal muscle cells
}

\author{
Lincor Darío ${ }^{1 \#}$, Musso Florencia ${ }^{2 \sharp}$, Vasconsuelo Andrea ${ }^{1}$, Faraoni María Belén ${ }^{2 *}$ and Milanesi \\ Lorena ${ }^{1 *}$ \\ 1 Instituto de Ciencias Biológicas y Biomédicas del Sur (INBIOSUR), Universidad Nacional del Sur - \\ CONICET, Bahía Blanca, Argentina. \\ 2 Instituto de Química del Sur (INQUISUR), Universidad Nacional del Sur - CONICET, Bahía Blanca, \\ Argentina. \\ * Correspondence: bfaraoni@criba.edu.ar; milanesi@criba.edu.ar \\ \# Both authors have equally contributed to this work
}

Academic Editor: name

Received: date; Accepted: date; Published: date

\begin{abstract}
Phytoestrogens are plant compounds which have generated considerable interests. A litany of health benefits including a lowered risk of osteoporosis, breast cancer, and menopausal symptoms, are frequently attributed to phytoestrogens but without the knowledge of their side effects. We investigate the effects of lipid extracts from the Solanaceae Nicotiana glauca on skeletal muscle cells, in relation to apoptosis. Opposite to the effects of $17 \beta$-estradiol, the crude extract from N. glauca and its sub-extracts induced apoptosis in $\mathrm{C} 2 \mathrm{C} 12$ cells. This apoptotic action involved caspase 3/7 activation. These data suggest that the traditional use of this medicinal plant could affect the skeletal muscle homeostasis.
\end{abstract}

Keywords: phytoestrogens, apoptosis, skeletal muscle, caspase 3/7, Nicotiana glauca, Solanaceae.

\section{Introduction}

In recent years, plants have gained many interests for being the vital sources of the discovery of pharmacologically active compounds [1,2]. Compounds from higher plants also called phytochemicals, serve as a source of new drugs for treating diverse forms of diseases. However, several pharmacological compounds from plants have been traditionally used without the actual knowledge of their side effects. In addition, the molecular mechanisms by which plant-derived compounds exert their effects are not yet fully understood.

Among diverse groups of phytochemicals, phytoestrogens have generated considerable interests as alternatives for hormone replacement therapy (HRT) or due to its preventative or therapeutic actions in carcinogenesis, atherosclerosis, and osteoporosis [3].

The phytoestrogens were first identified in the 1940s [4]. These plant compounds have got structural similarities with mammalian 17 $\beta$-estradiol (E2) and are capable of binding to estrogen receptors (ERs) [5-7]. Even though phytoestrogens can activate ERs, their effects are approximately thousand folds weaker than E2 [8]. They have been shown to possess estrogen like activity as they alleviate postmenopausal complaints, increase bone formation and repress adipose tissue similar to E2 [9]. Although there are many positive indications that phytoestrogens can fulfil those actions, it remains to be proven: controlled interventional studies are lacking, many side effects have not been evaluated and many questions remain unanswered.

As mentioned, the synthesis of molecules structurally and functionally related to the mammalian steroid hormones by plants, has been reported $[5,6,10,11]$. However, their physiological role in plants is controversial. Various steroids derived from plant and animal sources have been 
shown to affect cell growth and tissue differentiation in vascular plant systems. The existence of receptor-like molecules as those of animal cells could provide clues into a possible steroid mechanism of action.

In our previous works, we determined the relative contents of E2, estrone and progesterone like-molecules in Solanum glaucophyllum Desf. (Solanum malacoxylon Send.), Lycopersicon esculentum (Mill) and Nicotiana glauca (Graham) by competition assays using specific polyclonal antibodies against the respective mammalian steroid hormones [5,6,12]. Binding experiments with $\left[{ }^{3} \mathrm{H}\right] 17 \beta$-estradiol in the presence or absence of an excess of the unlabelled steroid showed that the Solanaceae organs contain estrogen binding sites. The protein nature of these sites was clearly indicated by their sensitivity to trypsin degradation. Likewise, lipid crude extracts from Solanaceae were able to compete with $\left[{ }^{3} \mathrm{H}\right] 17 \beta$-estradiol for binding to the estrogen receptor (ER) from breast cancer MCF-7 cells as well as with estrogen binding sites present in this plant species $[5,6,12]$.

Skeletal muscle was considered a non-classical estrogen target for a long time, though little is known about the effect of estrogens on this tissue. However, in recent years, both ERs have been found to be present in mouse, human, and pig skeletal muscle as well as in myoblasts from rat and mouse [13-16]. It is now known that estrogens exert actions in skeletal muscle. For example, muscle degenerative pathologies like sarcopenia, that is observed in menopausic women, are related to decreased levels of estrogens [17]. Also, estrogens have been shown to be an important factor in the protection of muscle from exercise-induced muscle damage [18]. Thus, the presence of ERs in skeletal muscle tissue and the capacity of phytoestrogens to bind to estrogen receptors, make this tissue a target for phytoestrogens actions.

Adult skeletal muscle increases its size and shows a remarkable capacity to adapt to trauma and injury. However, skeletal muscle cells are postmitotic and cannot replicate. Therefore, any increase in myonuclear number required for growth or repair of damaged muscle depends on satellite cells, a pool of myogenic precursor cells. This distinct population of mononucleated $[19,20]$ was first described by Mauro (1961) [21]. They owe their name to their localization under the basement membrane but outside the plasma membrane of the muscle fiber. Their colocalization with blood vessels [22] places satellite cells in an optimal position to respond to intrinsic signals from both the skeletal muscle fiber itself and from changes in the systemic environment. Satellite cells exist in a quiescent state after birth and begin to proliferate in response to regulatory factors during development and in cases of muscle injury [23-25]. Then, satellite cells are activated in response to both physiological stimuli, such as exercise, and to pathological conditions, such as injury and degenerative diseases. During development and regeneration, quiescent satellite cells are activated and start to proliferate. At this stage, they are often referred to as myogenic precursor cells or myoblasts [26]. The interest for us, is the presence of estrogen receptors (ERs) in satellite cells [14]. In addition, we demonstrated that E2 abrogates the apoptosis induced by oxidative stress in myoblasts through ERs [27]. Furthermore, during steroid-induced muscle growth, the hormone induces activation of muscle satellite cells [28]. Thus, this cells group that is relevant for the muscle physiology, could be affected by phytoestrogens.

Apoptosis can be triggered through the mitochondrial pathway or the death receptor-mediated pathway, both leading to caspase activation that ultimately results in nucleus condensation and DNA fragmentation [29,30]. As mentioned above, plant extracts exert many pharmacological functions, including apoptosis in tumor cells [31-33]. These apoptotic effects have been attributed to the presence of different compounds like phytosterols in the plant lipid extracts preferentially [34-36].

It is known that Solanaceae family provide significant amount of phytoestrogens [2,37]. Previously, we evidenced the presence of molecules functionally and structurally analogous to E2 in lipid extracts of the Solanaceaes [6].

The goal of the present study was to investigate the effects of lipid extracts from N. glauca on myoblastos, in relation to apoptosis; since apoptosis is a possible cause of diminution of satellite cells number in sarcopenia or other myopathies [38]. In addition, our aim was to contribute to the 
knowledge about the chemical structure of the phytoestrogens present in the lipid fraction of $N$. glauca, responsible of the effects observed on C2C12 cell line.

\section{Material and Methods}

\subsection{Materials}

Anti-phospho-Akt (Ser473) and anti-HSP27 antibodies were from Cell Signaling Technology Inc (Danvers, MA, USA).

Anti-beta tubulin (1:10000) antibody was obtained from Thermo Fisher Scientific, Inc (Rockford, IL, USA). DAPI and MitoTracker Red (MitoTracker Red CMXRos) dyes were from Molecular Probes (Eugene, OR, USA). The ECL blot detection kit was provided by Perkin-Elmer, Inc (Waltham, MA, USA). The protein molecular weight marker was from Amersham (Buckinghamshire, England). TUNEL assay kit was from Promega (Promega Corp., Madison, WI), Cell Event Caspase 3/7 detection reagent was from Invitrogen (Carlsbad,CA). All the other reagents used were of analytical grade.

\subsection{Plant Material}

Nicotiana glauca plant specimens were collected from their natural habitats in Buenos Aires Province, Argentina and were grown under green-house conditions.

\subsection{Extraction of lipid extracts}

The starting material plant was obtained from dried leaves of $N$. glauca $(126 \mathrm{~g})$, which was extracted for two times with $96 \%$ ethanol $(3 \mathrm{~L}$ ) at room temperature for 10 days. The ethanolic extract (crude extract) was concentrated under reduced pressure giving $26.3 \mathrm{~g}(21 \%)$. The residue was successively partitioned with hexane, chloroform and ethyl acetate. The extracted solutions were evaporated under reduced pressure and then lyophilized to yield $993 \mathrm{mg}(3.8 \%)$ of hexane sub-extract, $61 \mathrm{mg}(0.23 \%)$ of chloroform sub-extract and $164 \mathrm{mg}(0.62 \%)$ ethyl acetate sub-extract. 25 $\mathrm{mg}$ of final residue of each phase was solubilized in isopropanol $(5 \mathrm{ml})$ and was stored at $-20^{\circ} \mathrm{C}$.

\subsection{Phytochemical screening}

Phytochemical examinations were carried out for all the sub-extracts as per the standard methods [39]. For the detection of alkaloids was used the Dragendroff's test. The flavonoids were identified through the Fast Blue Salt reagent. The anthraquinones were detected using the Bornträger's test, and triterpenes and steroids were recognized using Libermann Burchard's test.

\subsection{Cell culture and treatment}

C2C12 murine skeletal myoblasts obtained from American Type Culture Collection (Manassas, VA, USA) were cultured in growth medium (DMEM) supplemented with $10 \%$ heat-inactivated (30 min, $568 \mathrm{C}$ ) fetal bovine serum, $1 \%$ nistatine, and $2 \%$ streptomycin. These highly myogenic cells have been widely used to study muscle functions [27,40,41]. The C2C12 cell line are murine myoblasts derived from satellite cells, whose behavior corresponds to that of progenitor lineage. This cell line is a subclone of C2 myoblasts [42] which spontaneously proliferate, differentiate and synthesize characteristic muscle proteins in culture $[43,44]$. Since C2C12 cells are comparable to satellite cells in muscle fibers [45], they represent an appropriate experimental model of them.

Cells were incubated at $37{ }^{\circ} \mathrm{C}$ in a humid atmosphere of $5 \% \mathrm{CO}_{2}$ in air. Cultures were passaged every 2 days with fresh medium. The treatments were performed with $70-80 \%$ confluent cultures $\left(120000\right.$ cells $\left./ \mathrm{cm}^{2}\right)$ in medium without serum for the time indicated in specific experiments. During this preincubation, cells were exposed to the crude extract from $N$. glauca (1:1000 dilution of the lipid extract in DMEM without serum), each sub-extract: hexane, chloroform and ethyl acetate or vehicle [0.001\% isopropanol (control)]; were added $20 \mathrm{~min}$ before induction of apoptosis with hydrogen 
peroxide $\left(\mathrm{H}_{2} \mathrm{O}_{2}\right) \quad 0.5 \mathrm{mM}$ at the times indicated (ranging from $30 \mathrm{~min}$ to $3 \mathrm{~h}$ ). The time and concentration range of the oxidant has been previously used to study apoptosis in $\mathrm{C} 2 \mathrm{C} 12$ cells $[27,41,46] . \mathrm{H}_{2} \mathrm{O}_{2}$ was diluted in culture medium without serum at a final concentration of $0.5 \mathrm{mM}$ in each assay. After treatments, cells were lysed using a buffer composed of $50 \mathrm{mM}$ Tris- $\mathrm{HCl}$ (pH 7.4), $150 \mathrm{mM} \mathrm{NaCl}, 0.2 \mathrm{mM} \mathrm{Na} 2 \mathrm{VO}_{4}, 2 \mathrm{mM}$ EDTA, $25 \mathrm{mM} \mathrm{NaF}, 1 \mathrm{mM}$ phenylmethylsulfonyl fluoride (PMSF), 1\% NP40, $20 \mathrm{mg} / \mathrm{ml}$ leupeptin, and $20 \mathrm{mg} / \mathrm{ml}$ aprotinin. Protein concentration was estimated by the method of Bradford (1976) [47], using BSA as standard. For microscopical assays, cells were cultured in chamber slides.

\subsection{Terminal Transferase dUTP Nick End Labeling (TUNEL) assays}

After the specific treatments, cells grown over coverslips, were processed for in situ localization of nuclei exhibiting DNA fragmentation by the technique of terminal deoxynucleotidyl transferase (TdT)-mediated dUTP digoxigenin nick-end labeling (TUNEL) with the use of the apoptosis detection kit DeadEndTM Fluorometric TUNEL System (Promega, Madison, WI). The protocols were followed according to the manufacturer's instructions. Then cells were mounted with $95 \%$ glycerol and analyzed by conventional fluorescence microscope (NIKON Eclipse Ti-S equipped with standard filter sets to capture fluorescent signals, and images were collected using a digital camera). At least 500 cells of each experimental condition were counted and apoptotic cells were identified by nuclei staining (TUNEL-positive cells). The results were expressed as percentage of apoptotic nuclei.

\subsection{Quantitation of apoptotic cells}

After treatments, cells were fixed with methanol at $-20{ }^{\circ} \mathrm{C}$ for $30 \mathrm{~min}$ and then washed with PBS. Fixed cells were incubated for $30 \mathrm{~min}$ at room temperature in darkness with 1:500 of a stock solution of DAPI $(5 \mathrm{mg} / \mathrm{ml})$ and next washed with PBS. Cells were mounted on glass slides and examined using a fluorescence microscope (NIKON Eclipse Ti-S) equipped with standard filter sets to capture fluorescent signals. Images were collected using a digital camera. Apoptotic cells were identified by the condensation and/or fragmentation of their nuclei. The results were expressed as percentage of apoptotic cells. A minimum of 500 cells was counted for each treatment from at least three independent experiments.

\subsection{MitoTracker red staining}

Coverslips with adherent cells were stained with MitoTracker red (Molecular Probes), which was prepared in dimethyl sulfoxide and then added to the cell culture medium at a final concentration of $1 \mathrm{mmol} / \mathrm{l}$. After 15 to $30 \mathrm{~min}$ incubation at $37^{\circ} \mathrm{C}$, cells were washed with PBS and fixed with methanol at $-20^{\circ} \mathrm{C}$ for $30 \mathrm{~min}$. Finally, the coverslips were analyzed by conventional fluorescence microscopy as described previously.

\subsection{Caspase-3/7 Activity Assay}

After specific treatments, cells were labeled with $6 \mu \mathrm{M}$ CellEventTM caspase-3/7 green detection reagent in PBS with calcium and magnesium for $30 \mathrm{~min}$ at $37^{\circ} \mathrm{C}$ in the dark. Finally, the stained cells were analyzed with a conventional fluorescence microscope (NIKON Eclipse Ti-S equipped with standard filter sets to capture fluorescent signals, and images were collected using a digital camera). At least 500 cells of each experimental condition were counted and activation of caspases were identified by green fluorescence in nuclei (Caspase-3/7-positive cells). The results were expressed as percentage of Caspase-3/7-positive cells.

\subsection{Western blot analysis}

Cell cultures were scrapped and resuspended using a lysis buffer (50 mM Tris-HCl, pH 7.4, 150 $\mathrm{mM}, \mathrm{NaCl}, 0.2 \mathrm{mM} \mathrm{Na} \mathrm{VO}_{4}, 2 \mathrm{mM}$ EDTA, $25 \mathrm{mM} \mathrm{NaF}, 1 \mathrm{mM}$ phenylmethylsulfonyl fluoride (PMSF), $20 \mathrm{mg} / \mathrm{ml}$ leupeptin, and $20 \mathrm{mg} / \mathrm{ml}$ aprotinin). Lysates were collected by aspiration and 
centrifuged at 12,000 g for $15 \mathrm{~min}$. The protein content of the supernatant was quantified by the Bradford procedure [47] using BSA as standard. Then, lysate proteins dissolved in Laemmli [48] sample buffer were separated on $10-12 \%$ SDS polyacrylamide gels and electrotransferred to polyvinylidene difluoride membranes. Relative migration of unknown proteins was determined by comparison with molecular weight colored markers (Amersham, Piscataway, NJ, USA). Membranes were blocked $1 \mathrm{~h}$ at room temperature in PBS-T buffer (PBS 0.1\% Tween-20) containing 5\% dry milk. Membranes were incubated with different primary antibodies overnight at $4{ }^{\circ} \mathrm{C}$, then washed three times in PBS-T and incubated in PBS-T containing $1 \%$ dry milk with peroxidase conjugated secondary antibodies for $1 \mathrm{~h}$ at room temperature. Next, membranes were visualized using an enhanced chemiluminescent technique according to the manufacturer's instructions. For reprobing with other antibodies, membranes were incubated in stripping buffer $(62.5 \mathrm{mM}$ Tris- $\mathrm{HCl}, \mathrm{pH} 6.8,2 \%$ SDS, and $50 \mathrm{mM}$ mercaptoethanol) for $30 \mathrm{~min}$ at $55^{\circ} \mathrm{C}$, washed for $10 \mathrm{~min}$ in PBS-T, and then blocked and blotted as described above.

\subsection{Statistical analysis}

Data analysis was performed using standard statistical packages (InfoStat System, Córdoba, Argentina [49]. All values are shown as the mean \pm S.D. of at least three independent experiments. The data were considered statistical significant when $\mathrm{P}<0.05$.

\section{Results}

\subsection{Crude extract from Nicotiana glauca induces apoptosis in skeletal muscle cells}

In previous work, we observed that $\mathrm{E} 2$ abrogates $\mathrm{H}_{2} \mathrm{O}_{2}$-induced apoptosis of $\mathrm{C} 2 \mathrm{C} 12$ myogenic cells [27]. Now we investigate whether the lipid extracts from N. glauca also act as the hormone. C2C12 cells were challenged with crude extract during the times indicated and apoptotic events were investigated (Methods). The nuclear dye DAPI showed morphological changes typical of apoptosis such as nuclear fragmentation/condensation (pyknotic nuclei) after treatment with the crude extract from N. glauca, which represented near to $70 \%$ of the cultured muscle cells in similar fashion as those treated with $\mathrm{H}_{2} \mathrm{O}_{2} 0.5 \mathrm{mM}$ (data not shown). In addition, morphological changes and cellular redistribution of mitochondria could be detected in $\mathrm{C} 2 \mathrm{C} 12$ cells treated with ethanolic extract from N. glauca and then stained with the fluorescent mitochondrial probe MitoTracker red (Methods) as described above. Thus, Figure 1 shows that cells treated with vehicle (control) display 'spiderweb' or uniform distribution of mitochondria through the cytosol. On the other hand, when apoptosis was induced with $\mathrm{H}_{2} \mathrm{O}_{2}$ or the cells were treated with the crude extract, we observed reduced mitochondria size, 'pyknotic', and characteristic clustering of the organelles around the nucleus (which represented near to $70 \%$ of the cultured muscle cells), events associated to apoptosis. To confirm those observations, we evaluated the effects of the crude extract from N. glauca on skeletal muscle cells by TUNEL assays (Figure 2). We perform the same experimental conditions as before. Cells treated with the crude extract exhibited a large increase in DNA fragmentation $(63 \% \pm$ 9.09 of TUNEL positive cells above the control), similar to the values obtained with $\mathrm{H}_{2} \mathrm{O}_{2}$ treatment (Figure 2). 


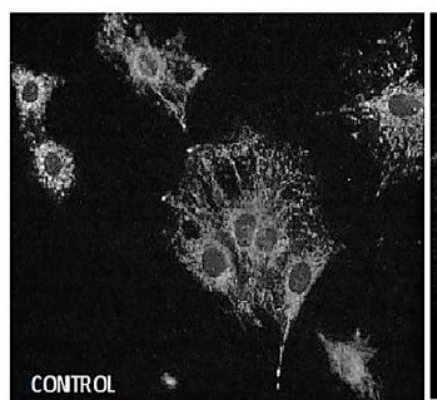

(a)

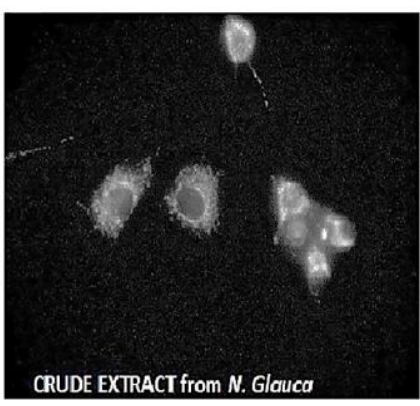

(b)

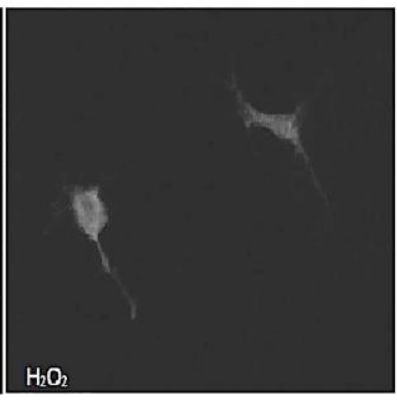

(c)

Figure 1. Crude extract from N. glauca induce changes in morphology and localization of mitochondria in C2C12 muscle cells. C2C12 cells grown on coverslips as $60-70 \%$ confluent monolayers were treated (see below), stained with MitoTracker Red, and fixed with methanol as described under Materials and Methods Section. (a) Untreated cells. (b) Cells treated with crude extract (1:1000 dilution) during $2 \mathrm{~h}$. (c) Cells treated with $\mathrm{H}_{2} \mathrm{O}_{2} 0.5 \mathrm{mM}$ during $2 \mathrm{~h}$. Untreated cells present normal mitochondrial morphology and distribution throughout the entire cell distant to the nucleus or display 'spiderweb' mitochondria; but cells treated with the crude extract exhibit mitochondria clustered around the nucleus with condensed or pyknotic aspect as cells treated with $\mathrm{H}_{2} \mathrm{O}_{2}$. At least ten fields per slide and three independent cultures were examined. Representative photographs are shown. Magnification: 63X.

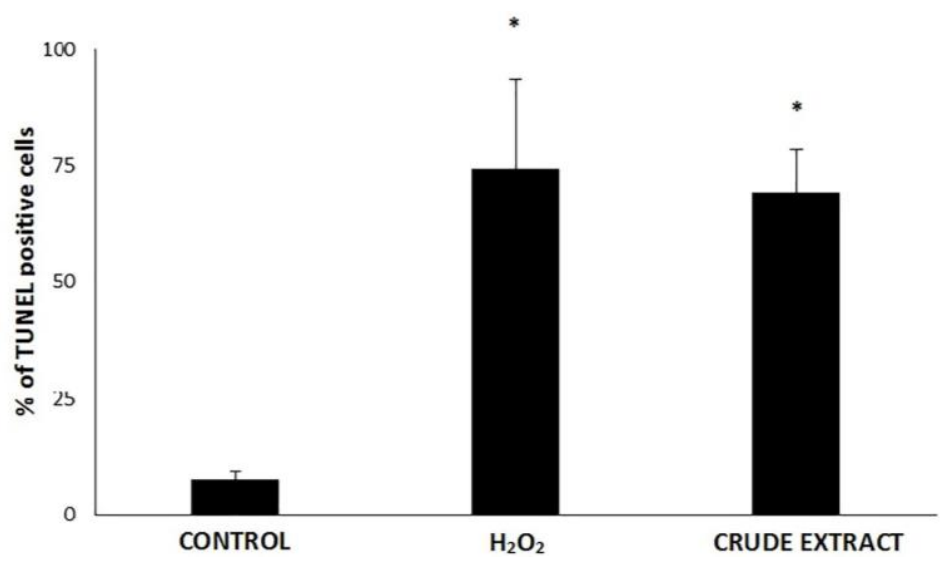

Figure 2. Crude extract from $N$. glauca induces apoptosis in $\mathrm{C} 2 \mathrm{C} 12$ cells. C2C12 cells untreated (CONTROL) or incubated with crude extract from N. glauca for $1 \mathrm{~h}$ (CRUDE EXTRACT) or with the apoptotic inducer $\mathrm{H}_{2} \mathrm{O}_{2}(0.5 \mathrm{mM}, 2 \mathrm{~h})$. Then, apoptosis was determined by TUNEL assays as described under Materials and Methods Section and expressed as the percentage of TUNEL positive cells in the coverslips. Each value represents the mean of three independent determinations $\pm \mathrm{SD} ;{ }^{*} \mathrm{P}<0.05$ with respect to the control.

\subsection{Crude extract from Nicotiana glauca induced Apoptosis involves Caspase-3/7}

Within the caspase family, the effector caspases-3 and -7, orchestrate the destruction phase of apoptosis that results in the controlled dismantling of a range of key proteins within the cell and its subsequent disposal [50]. Moreover, one of the most evident and specific features of apoptosis is the degradation of the DNA into numerous fragments, driven by the activation of caspase-3 [51], the central effector caspase, which makes it an attractive biomarker of apoptosis. To address whether the apoptotic action of the crude extract from $N$. glauca on $\mathrm{C} 2 \mathrm{C} 12$ muscle cells is exerted through caspases 3/7 activation, C2C12 cells were treated with ethanolic extract as before (Methods) and analyzed by fluorescent microscopy using the specific Cell Event Caspase 3/7 detection probe. As shown in Figure 3, the crude extract induces the caspases 3/7 activation $(86 \% \pm 7.21$ of caspase positive cells above the control) in similar fashion as hydrogen peroxide. 


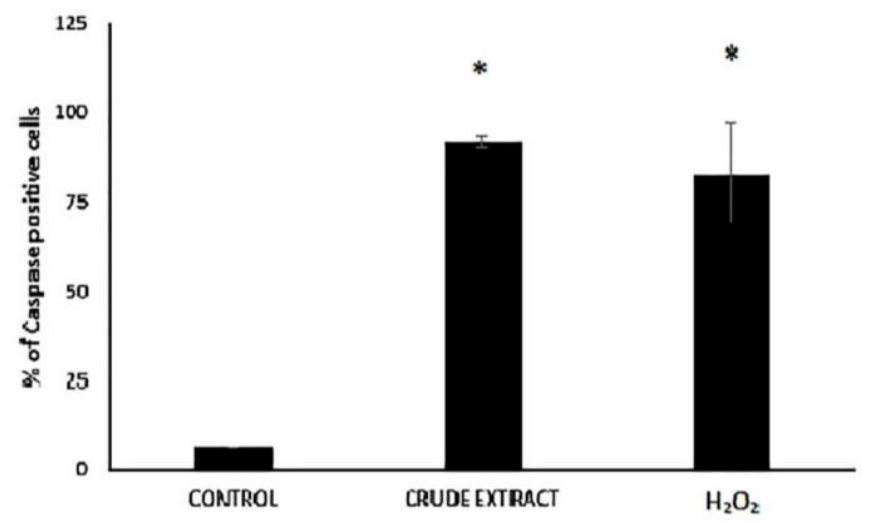

Figure 3. Crude extract from $N$. glauca induces Caspase 3/7 activation. C2C12 cells grown on coverslips as $60-70 \%$ confluent monolayers were treated with the indicated stimuli as before and were analyzed for caspase activation using Cell Event Caspase 3/7 detection probe (Methods). (CONTROL) untreated cells, (CRUDE EXTRACT) cells incubated with crude extract from N. glauca for $1 \mathrm{~h}$ to $2 \mathrm{~h},\left(\mathrm{H}_{2} \mathrm{O}_{2}\right)$ cells treated with $\mathrm{H}_{2} \mathrm{O}_{2}(0.5 \mathrm{mM}, 1 \mathrm{~h}$ to $2 \mathrm{~h})$. Experiments were repeated at least three times with essentially identical results. \pm SD; ${ }^{*} \mathrm{P}<0.05$ with respect to the control.

\subsection{Effect of hexane, chloroform and ethyl acetate sub-extracts from Nicotiana glauca}

With the aim to characterize the chemical structure of the apoptotic effectors present in the crude extract of N. glauca, extraction procedure with solvents was carried out (Methods). Thus, crude extract of $N$. glauca was partitioned with hexane, chloroform and ethyl acetate (Methods) and each sub-extract was tested for apoptotic activity in skeletal muscle cells by TUNEL assays and caspases activation. Regards caspase activation, the assay indicated that hexane and to a lesser extent chloroform sub-extracts $(90 \% \pm 4.6$ and $55 \% \pm 14$ of caspase positive cells above the control, respectively ) induce apoptosis activating caspases $3 / 7$ (Figure 4). The same results were obtained, evaluating the caspase activation through flow cytometry (data not shown). Congruent with this data, TUNEL assays shown that hexane and to a lesser extent chloroform and ethyl acetate sub-extracts are able to induce apoptosis $(98 \% \pm 1.01,67 \% \pm 18.38,44.6 \% \pm 12.7$ TUNEL positive cells respectively) (Figure 4).

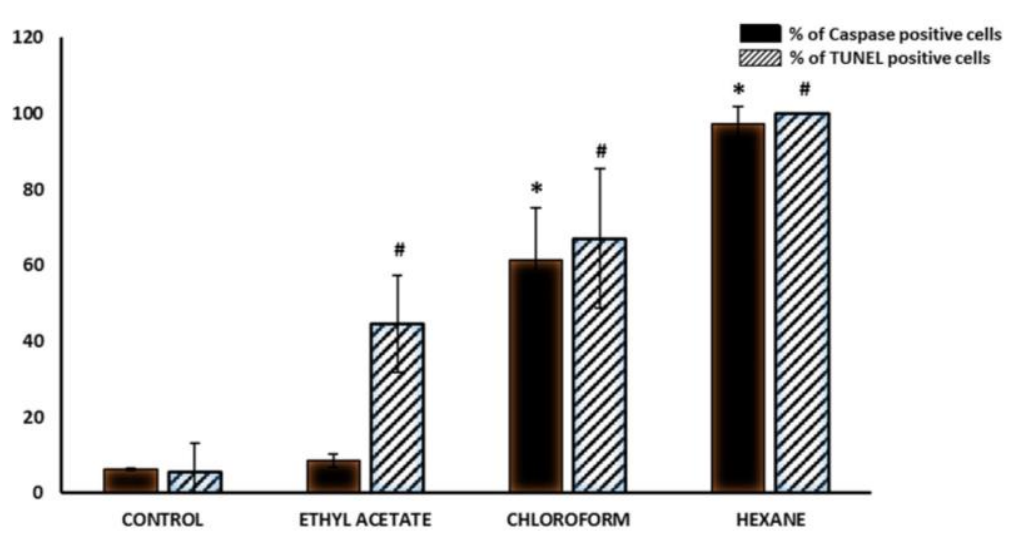

Figure 4. Hexane, chloroform and ethyl acetate sub-extracts from $N$. glauca induce apoptosis through caspase 3/7 in C2C12 cells. C2C12 cells were treated with the indicated stimuli (ETHYL ACETATE, CHLOROFORM or HEXANE) as before. CONTROL, untreated cells. Then, apoptosis was determined by TUNEL assays as described under Materials and Methods Section and expressed as the percentage of TUNEL positive cells in the coverslips. Likewise, other cultures were treated with sub-extracts as before and were analyzed for caspase activation using Cell Event Caspase 3/7 detection probe (Methods). Each value represents the mean of three independent determinations $\pm \mathrm{SD} ;{ }^{*} \mathrm{P}<0.05$ with respect to the control. 


\subsection{Lipid extracts obtained from Nicotiana glauca activate stress signaling}

Against a potentially damaging stresses the cell activates its defense mechanism/survival signaling pathways, as a first and rapid response that allows to tolerate and/or to recover from the damage imposed. As injury continues, such mechanisms are no longer sufficient. Thus, when the injurious signal persists and exceeds the mechanisms of survival, the net effect is the cell death. Among the cellular responses to stress, here we evaluated HSP27 and Akt phosphorylation levels in response to the lipid sub-extracts obtained from $N$. glauca crude extract. $\mathrm{C} 2 \mathrm{C} 12$ cell cultures were incubated with each sub-extract during 30 min followed by measurement of HSP27 and Akt phosphorylation by immunoblot analysis of cell lysates. As shown in Figure 5, Western blot analysis using anti-phospho-Akt and anti-phospho-HSP27 antibodies revealed Akt and HSP27 activation (phosphorylation) in response to hexane, chloroform and ethyl acetate sub-extracts treatments. Immunocytochemistry studies using fluorescent microscopy and the same antibodies were congruent with the Western blot results, Figure 6 .

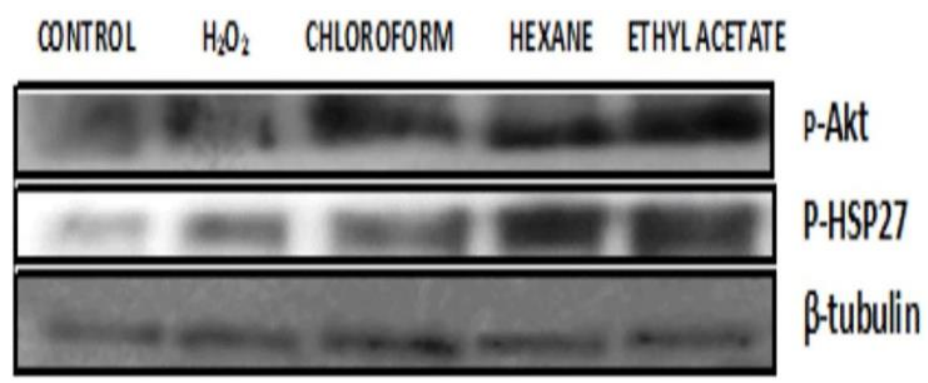

Figure 5. Hexane, chloroform and ethyl acetate sub-extracts from crude extract from N. glauca trigger Akt and HSP27 phosphorylation. $\mathrm{C} 2 \mathrm{C} 12$ cells were treated with the indicated stimuli (CHLOROFORM, HEXANE, ETHYL ACETATE or $\mathrm{H}_{2} \mathrm{O}_{2}$ ) as before. CONTROL, untreated cells. Cell lysate proteins from each condition containing equivalent protein amounts $(25 \mathrm{mg})$ were fractionated by SDS-PAGE, transferred to PVDF membranes, and western blotted with Phospho-Akt or Phospho-HSP27 antibodies as described in Materials and Methods Section. B-tubulin levels are shown as protein loading control. Immunoblots representative are shown. 


\section{P-HSP27}
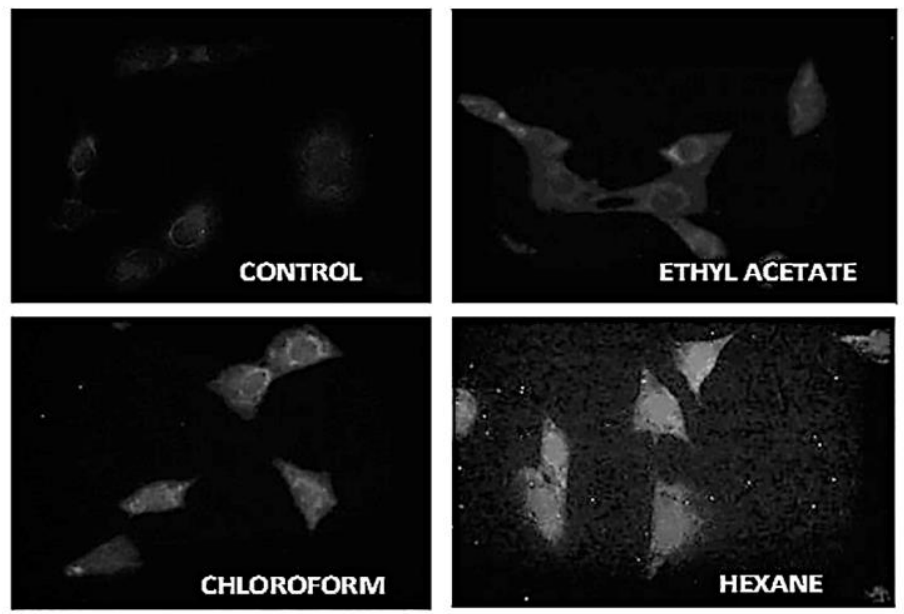

P-Akt
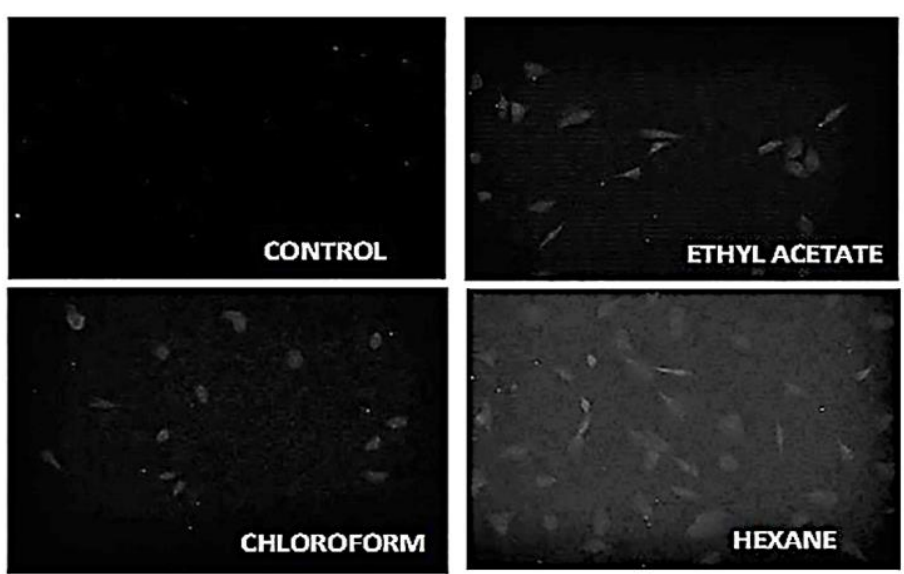

Figure 6. Hexane, chloroform and ethyl acetate sub-extracts from crude extract from N. glauca trigger Akt and HSP27 phosphorylation. $\mathrm{C} 2 \mathrm{C} 12$ cells were treated with the indicated stimuli (CHLOROFORM, HEXANE, ETHYL ACETATE or $\mathrm{H}_{2} \mathrm{O}_{2}$ ) as before. CONTROL, untreated cells. Fluorescence microscopy of p-HSP27 and p-Akt phosphorylation. HSP27 or Akt phosphorylated (green fluorescence) were stained by using anti- phospho-HSP27 or anti- phospho-Akt primary antibody, respectively and Alexa 488-conjugated secondary antibody. Experiments were repeated at least three times with essentially identical results (Magnification for P-Akt: 20x and for P-HSP27: 63x).

\section{Discussion}

As was described in Introduction, Solanaceae family provide significant amount of phytoestrogens [37]. Phytoestrogens are supplements and widely marketed as a natural alternative to estrogen replacement therapy or to treat a wide range of health conditions. The risk of adverse effects of its use, however, has not been fully studied. Moreover, the molecular mechanism of the side effects is unknown for much of them.

In this work, the murine skeletal muscle cells were treated with a crude ethanol extract from $N$. glauca, with the lipid sub-extracts obtained from that or with $\mathrm{H}_{2} \mathrm{O}_{2}$ as a positive control of apoptosis. As a first approach we evaluated the effects of those treatments seeing the cellular morphology using DAPI and mitotracker dyes. Cells exposed to the crude extract, to the hexane or to the chloroform sub-extracts shown typical apoptotic morphology (nuclear condensation / fragmentation, mitochondrial picnosis and clustering of the organelle near the nucleus) similar to $\mathrm{H}_{2} \mathrm{O}_{2}$ treatment. Opposing to ours previous works in which we observed that $17 \beta$-estradiol protects the skeletal muscle cells inhibiting the $\mathrm{H}_{2} \mathrm{O}_{2}$ - induced apoptosis [52], here we found that the crude 
extract and sub-extracts of hexane and chloroform from N. glauca induced apoptosis in C2C12 cells. Indeed, in accordance with the results from Tunel assays, we found an important activation of caspases when cells were treated with the lipid hexane and chloroform sub-extracts, being the hexane sub-extract the most potent. On the other hand, the ethyl acetate sub-extract was unable to induce higher levels of apoptosis, throwing values similar to controls. These results suggest that molecules of lipidic nature, concentrated preferentially in the hexane and in less part, the chloroform sub-extracts, are responsible for the apoptotic stimuli.

We have also observed that short treatments times $(30 \mathrm{~min}$ ) with the sub-extracts from $N$. glauca, induced the activation of a rapid cellular defense response with Akt and HSP27 activation as it was observed in previous works with $\mathrm{H}_{2} \mathrm{O}_{2}$ as the apoptotic inductor [52] . Indicating, that cells sense an injury from those treatments. However, when we perform longer treatments ( 1 to $2 \mathrm{~h}$ ) (data not shown), cells were unable to sustain those survival response and turn into apoptosis.

Finally, in this work, we were interested to beginning with the identification of the molecular actors during the apoptotic signaling induced by the lipid extracts. For the first approaches we analyze caspase activity. In this assay the substrate (amino acid peptide DEVD) used to evaluate the caspase activation is recognized by both caspases 3 and 7. In view of this, our results suggest that the compounds from $N$. glauca trigger apoptosis involving caspase pathways, but we are unable by this method to identify the specific caspase involved.

These results, opposite to those observed by us with E2, are in agreement with the different behaviors of phytoestrogens due their diverse ways to bind the ERs. Indeed, they can act like partial ER agonists or antagonists [53]. The differential effects of agonists and antagonists on receptor activity in a given cell context have been ascribed to different conformations of the receptor ligand complex, as well as by differences in the interaction with transcriptional coactivator and corepressor proteins and other transcription factors. In addition, to increase the complexity of molecular mechanisms that mediate the phytoestrogens effects, it have been demonstrated that these compounds have additional cellular activities not ascribed to activation of the ERs, such as regulation of cell-signaling pathways [53,54].

With the aim to obtain some knowledge about the chemical structure of the compounds responsible of the effects here observed on satellite cells, we performed phytochemical screening of the sub-extracts from $N$. glauca. We observed the presence of flavonoids, anthraquinones, triterpenes and steroids in the sub-extracts of hexane and chloroform. The presence of alkaloids in these sub-extracts was not observed. In the ethyl acetate sub-extract the presence of all the chemical structures examined was detected, but probably, are present in a low concentration respect the others sub-fractions. An exciting prospect of the future research orientated to identify the compounds of hexane and chloroform sub-extracts lies in comprehension of their properties and complete determination of benefit/risk ratio.

The data reported here, on the effects of lipid extracts from $N$. glauca on myoblasts suggest that a possible use of this medicinal plant could affect the skeletal muscle homeostasis. Since, muscle satellite cells are critical for successful muscle regeneration and repair [55]. Thus, a possible compound to use in hormone replacement therapy to overcome menopausal symptoms like osteoporosis, could affect skeletal muscle leading to sarcopenia. Increasing the ageing symptoms. Clearly, additional studies are then necessary to further elucidate the signaling mechanisms, which mediate the apoptotic action of compounds from N. glauca in skeletal muscle cells. This knowledge may be of relevance to develop strategies for avoid undesirable side effects increasing the potential as natural pharmaceutical compound of phytoestrogens.

Acknowledgments: This research was supported by grant from the Consejo Nacional de Investigaciones Científicas y Técnicas (CONICET); Grant number: PIP11220110100544. A.V. and L.M. are researcher members of CONICET, M.B.F. is research member of CIC, D.L. and F.A.M. thank the CONICET for a doctoral fellowship.

Author Contributions: L.M., M.B.F. and A.V. conceived and designed the experiments; D.L. and F.A.M. performed the experiments; L.M. maintain the cellular cultures; L.M., M.B.F. and A.V. interpreted the results, contributed reagents/materials/analysis tools and wrote the paper. 
Conflicts of Interest: The authors declare no conflict of interest.

\section{References}

1. Mustapha, A. Medicinal plants with possible anti- HIV activities: A Review. International Journal of Medicinal Plants 2014, 106, 439-453.

2. Hassan, L.E.; Ahamed, M.B.; Majid, A.S.; Baharetha, H.; Muslim, N.; Nassar, Z.; et al. Correlation of antiangiogenic, antioxidant and cytotoxic activities of some Sudanese medicinal plants with phenolic and flavonoid contents. BMC Complement Altern Med 2014, 14, 406, 10.1186/1472-6882-14-406

3. Patisaul, H.; Jefferson, W. The pros and cons of phytoestrogens. Front Neuroendocrinol 2010, 31, 400-419, 10.1016/j.yfrne.2010.03.003

4. Bennets, H.; Underwood, E.; Shier, F. A Specific Breeding Problem of Sheep on Subterranean Clover Pastures in Western Australia. Aust Vet J 1946, 22, 2-12, 10.1111/j.1751-0813.1946.tb15473.x

5. Milanesi, L.; Monje, P.; Boland, R. Presence of estrogens and estrogen receptor-like proteins in Solanum glaucophyllum. Biochem Biohys Res Commun 2001, 289, 1175-1179, 10.1006/bbrc.2001.6079

6. Milanesi, L.; Boland, R. Presence of estrogen receptor(ER)-like proteins and endogenous ligands for ER in Solanaceae. Plant Science 2004, 166, 397-404, 10.1016/j.plantsci.2003.10.006

7. Pilsakova, L.; Riecansky, I.; Jagla, F. The physiological actions of isoflavone phytoestrogens. Physiological Research 2010, 59, 651-664.

8. Pelissero, C.; Bennetau, B.; Babin, P.; LeMenn, F.; Dunogues, J. The estrogenic activity of certain phytoestrogens in the Siberian sturgeon Acipenser baeri. J Steroid Biochem 1991, 38, 293-299, 10.1016/0960-0760(91)90100-J

9. Song, W.; Chun, O.; Hwang, I.; Shin, H.; Kim, B.; Kim, K, et al. Soy isoflavones as safe functional ingredients. J Med Food 2007, 10, 571-580, 10.1089/jmf.2006.0620

10. Agarwal, M. Receptors for mammalian steroid-hormones in microbes and plants. FEBS Lett 1993, 322, 207-210, 10.1016/0014-5793(93)81570-P

11. Geuns, J. Steroid hormones and plant growth and development. Phytochem 1978, 17, 1-14, 10.1016/S0031-9422(00)89671-5

12. Milanesi, L. Clonado y caracterización molecular de las hidroxilasas de vitamina D de Solanum glaucophyllum. Doctoral Thesis, Universidad Nacional del Sur, Bahía Blanca, Argentina, 2004.

13. Barros, R.P.; Machado, U.F.; Warner, M.; Gustafsson, J.A. Muscle GLUT4 regulation by estrogen receptors ERbeta and ERalpha. Proc Natl Acad Sci USA 2006, 103, 1605-1608, 10.1073/pnas.0510391103

14. Kalbe, C.; Mau, M.: Wollenhaupt, K.; Rehfeldt, C. Evidence for estrogen receptor alpha and beta expression in skeletal muscle of pigs. Histochem Cell Biol 2007, 127, 95-107, 10.1007/s00418-006-0224-z

15. Lemoine, S.; Granier, P.; Tiffoche, C.; Berthon, P.M.; Rannou-Bekono, F; Thieulant, M.L; et al. Effect of endurance training on oestrogen receptor alpha transcripts in rat skeletal muscle. Acta Physiol Scand 2002, 174, 283-289, 10.1046/j.1365-201x.2002.00943.x

16. Milanesi, L.; Vasconsuelo, A.; de Boland, A.R.; Boland, R. Expression andsubcellular distribution of native estrogen receptor beta in murine C2C12 cellsand skeletal muscle tissue. Steroids 2009, 6, 489-497, 10.1016/j.steroids.2009.01.005

17. Milanesi, L.; de Boland, A.R.; Boland, R. Expression and localization of estrogen receptor alpha in the C2C12 murine skeletal muscle cell line. J Cell Biochem 2008, 104, 1254-1273, 10.1002/jcb.21706

18. Dionne, I.J.; Kinaman, K.A.; Poehlman, E.T. Sarcopenia and muscle function during menopause and hormone-replacement therapy. J Nutr Health Aging 2000, 4, 156-161.

19. Campion, D.R. The muscle satellite cell-a review. Int Rev Cytol 1984, 87, 225-251, 10.1016/S0074-7696(08)62444-4

20. Grounds, M.D.; White, J.; Rosenthal, N.; Bogoyevitch, M. The role of stem cells in skeletal and cardiac muscle repair. J Histochem Cytochem 2002, 50, 589-610, 10.1177/002215540205000501

21. Mauro, A. Satellite cell of skeletal muscle fibers. J Biophys Biochem Cytol 1961, 9, 493-495, 10.1083/jcb.9.2.493

22. Ryall, J.G.; Schertzer, J.D.; Lynch, G.S. Cellular and molecular mechanisms underlying age-related skeletal muscle wasting and weakness. Biogerontology 2008, 9, 213-228, 10.1007/s10522-008-9131-0

23. Allen, R.E.; Rankin, L. Regulation of satellite cells during skeletal muscle growth and development. Proc Soc Exp Biol Med 1990, 194, 81-86, 10.3181/00379727-194-43060 
24. Allen, D.; Chen, L.; Seaber, A.; Urbaniak, J. Calcitonin gene-related peptide and reperfusion injury. J Orthop Res 1997, 15, 243-248, http://dx.doi.org/10.1002/jor.1100150213

25. Cornelison, D.; Wold, B. Single-cell analysis of regulatory gene expression in quiescent and activated mouse skeletal muscle satellite cells. Dev Biol 1997, 191, 270-283, 10.1006/dbio.1997.8721

26. Charge, S.B.; Rudnicki, M.A. Cellular and molecular regulation of muscle regeneration. Physiol Rev 2004, 84, 209-238, 10.1152/physrev.00019.2003

27. Vasconsuelo, A.; Milanesi, L.; Boland, R. 17 $\beta$-Estradiol abrogates apoptosis in murine skeletal muscle cells through estrogen receptors: role ofthe phosphatidylinositol 3-kinase/Akt pathway. J Endocrinol 2008, 196, 385-397, 10.1677/JOE-07-0250

28. Deasy, B.; Lu, A.; Tebbets, J.; Feduska, J.; Schugar, R.; Pollett, J.; Sun, B.; et al. A role for cell sex in stem cell-mediated skeletal muscle regeneration: female cells have higher muscle regeneration efficiency. J Cell Biol 2007, 177, 73-86, 10.1083/jcb.200612094

29. Earnshaw, W.C.; Martins, L.M.; Kaufmann, S.H. Mammalian caspases: structures, activation, substrates, and functions during apoptosis. Annu Rev Biochem 1999, 68, 383-424, 10.1146/annurev.biochem.68.1.383

30. Nagata, S.; Nagase, H.; Kawane, K.; Mukae, N.; Fukuyama, H. Degradation of chromosomal DNA during apoptosis. Cell Death Differ 2003, 10, 108-116, 10.1038/sj.cdd.4401161

31. Liu, J.; Li, Y.; Ren, W.; Hu, W.X. Apoptosis of HL-60 cells induced by extracts from Narcissus tazetta var. chinensis. Cancer Lett 2006, 242, 133-140, 10.1016/j.canlet.2005.11.023

32. Benarba, B.; Meddah, B.; Aoues, A. Bryonia dioica aqueous extract induce apoptosis through mitochondrial intrinsic pathway in BL41 Burkitt's lymphoma cells. J Ethnopharmacol 2012, 141, 510-516, 10.1016/j.jep.2012.02.052

33. Rezaei, P.F.; Fouladdel, S.; Hassani, S.; Yousefbeyk, F.; Ghaffari, S.M.; Amin, G.; et al. Induction of apoptosis and cell cycle arrest by pericarp polyphenol-rich extract of Baneh in human colon carcinoma HT29 cells. Food Chem Toxicol 2012, 50, 1054-1059, 10.1016/j.fct.2011.11.012

34. Ramos, S. Effects of dietary flavonoids on apoptotic pathways related to cancer chemoprevention. J Nutr Biochem 2007, 18, 427-442, 10.1016/j.jnutbio.2006.11.004

35. Cai, X.; Ye, T.; Liu, C.; Lu, W.; Lu, M.; Zhang, J.; et al. Luteolin induced G2 phase cell cycle arrest and apoptosis on non-small cell lung cancer cells. Toxicol In Vitro 2012, 25, 1385-1391, 10.1016/j.tiv.2011.05.009

36. Huang, W.Y.; Cai, Y.Z.; Zhang, Y. Natural phenolic compounds from medicinal herbs and dietary plants: potential use for cancer prevention. Nutr Cancer 2010, 62, 1-20, 10.1080/01635580903191585

37. Preedy, V.; Watson, R. Bioactive Foods in Promoting Health: Fruits and Vegetables, 1st ed.; Academic Press: London, UK, 2009; pp. 1-754, 978-0-123-74628-3.

38. La Colla, A.; Pronsato, L.; Milanesi, L.; Vasconsuelo, A. 17 $\beta$-Estradiol and testosterone in sarcopenia: Role of satellite cells. Ageing Res Rev 2015, 24, 166-77, 10.1016/j.arr.2015.07.011

39. Wagner, H.; Bladt, S.; Zgainski, E. Plant Drug Analysis, 1st ed.; Springer: Berlin, Germany, 1984; pp. 1-309, 978-3-662-02400-3.

40. Burattini, S.; Ferri, P.; Battistelli, M.; Curci, R.; Luchetti, F.; Falcieri, E. C2C12 murine myoblasts as a model of skeletal muscle development: Morphofunctional characterization. Eur J Histochem 2004, 48, 223-233, 10.4081/891

41. Pronsato, L.; Milanesi, L.; Boland, R. Testosterone exerts antiapoptotic effects against $\mathrm{H}_{2} \mathrm{O}_{2}$ in $\mathrm{C}_{2} \mathrm{C} 12$ skeletal muscle cells through the apoptotic intrinsic pathway. J Endocrinol 2012, 212, 371-381, 10.1530/JOE-11-0234

42. Yaffe, D.; Saxel, O. Serial passaging and differentiation of myogenic cellsisolated from dystrophic mouse muscle. Nature 1977, 270, 725-727, 10.1038/270725a0

43. Blau, H.; Chiu, P.; Webster, C. Cytoplasmic activation of human nucleargenes in stable heterocaryons. Cell 1983, 32, 1171-1180, 10.1016/0092-8674(83)90300-8

44. Patz, T.; Doraiswamy, A.; Narayan, R.J.; Modi, R.; Chrisey, D.B. Two dimensional differential adherence and aligment of C2C12 myoblasts. Mater Sci Eng B 2005, 123, 242-247, 10.1016/j.mseb.2005.08.088

45. Yoshida, N.; Yoshida, S.; Koishi, K.; Masuda, K.; Nabeshima, Y. Cell heterogeneity upon myogenic differentiation: Down-regulation of Myod and Myf-5 generates 'reserve cells'. J Cell Sci 1998, 111, 769-779.

46. Siu, P.M.; Pistilli, E.; Always, S. Age-dependent increase in oxidative stressin gastrocnemius muscle with unloading. J Appl Physiol 2009, 105, 1695-1705, 10.1152/japplphysiol.90800.2008

47. Bradford, M. A. Rapid and sensitive method for the quantitation of microgram quantities of protein utilizing the principle of protein-dye binding. Anal Biochem 1976, 72, 248-254, 10.1016/0003-2697(76)90527-3 
48. Laemmli, U. Cleavage of structural proteins during the assembly of the head of bacteriophage T4. Nature 1970, 227, 680-685, 10.1038/227680a0

49. Di Rienzo, J.; Casanoves, F; Balzarini, M.; Gonzalez, L.; Tablada, M.; Robledo, C.W. InfoStat versión 2014. Grupo InfoStat, FCA, Universidad Nacional de Córdoba, Argentina. http://www.infostat.com.ar

50. Taylor, R.C.; Cullen, S.P.; Martin, S.J. Apoptosis: Controlled demolition at the cellular level. Nat Rev Mol Cell Biol 2008, 9, 231-241, 10.1038/nrm2312

51. Porter, A.; Janicke, R. Emerging roles of caspase-3 in apoptosis. Cell Death Differ 1999, 6, 99-104, 10.1038/sj.cdd.4400476

52. Vasconsuelo, A.; Pronsato, L.; Ronda, A.C.; Boland, R.; Milanesi, L. Role of 17 $\beta$-estradiol and testosterone in apoptosis. Steroids 2011, 76, 1223-1231, 10.1016/j.steroids.2011.08.001

53. Harris, D.; Besselink, E.; Henning, S.; Go, L.; Heber, D. Phytoestrogens induce differential estrogen receptor alpha- or beta- mediated responses in transfected breast cancer cells. Exp Biol Med 2005, 230, 558-568, 10.1177/153537020523000807

54. Limer, J.; Speirs, V. Phytoestrogens and breast cancer chemoprevention. Breast Cancer Res 2004, 6, 119-127, 10.1186/bcr781

55. Chang, N.C.; Rudnicki, M.A. Satellite cells: the architects of skeletal muscle. Curr Top Dev Biol 2014, 107, 161-181, 10.1016/B978-0-12-416022-4.00006-8

(C) 2017 by the authors. Submitted for possible open access publication under the terms and conditions of the Creative Commons Attribution (CC BY) license (http://creativecommons.org/licenses/by/4.0/). 